DOI: http://dx.doi.org/10.4314/star.v4i2.15 ISSN: 2226-7522(Print) and 2305-3372 (Online) Science, Technology and Arts Research Journal Sci. Technol. Arts Res. J., April-June 2015, 4(2): 122-126 Journal Homepage: http://www.starjournal.org/

Original Research

\title{
Response of Swayne's Hartebeest to Fire-induced Habitat Change in Senkelle Sanctuary, Ethiopia
}

\author{
Abiot Hailu ${ }^{1,3}$, Abdella Gure ${ }^{1}$, Girma Mengesha ${ }^{1}$, Yosef Mamo ${ }^{2}$ and Addisu Asefa ${ }^{3^{*}}$ \\ ${ }^{1}$ Wondo Genet College of Forestry and Natural Resources, Post Box: 128, Shashamane, Ethiopia \\ ${ }^{2}$ Department of Biology, Hawassa University, Post Box: 05, Hawassa, Ethiopia \\ ${ }^{3}$ Ethiopian Wildlife Conservation Authority, Post Box 386, Addis Ababa, Ethiopia
}

\begin{tabular}{|c|c|}
\hline \multirow{16}{*}{$\begin{array}{l}\text { Abstract } \\
\text { Fire disturbance is one principal conservation tool to improve wildlife habitat quality in } \\
\text { savanna ecosystems, but it can also have the opposite effect if unregulated as it favors } \\
\text { the growth and establishment of invasive alien species and bush encroachment by } \\
\text { indigenous species. The main aim of the present study was to examine the response of } \\
\text { Swayne's Hartebeest (Alcelaphus buselaphus swaynei), a globally endangered } \\
\text { Ethiopian endemic subspecies to fire-induced habitat disturbance in Senkelle Swayne's } \\
\text { Hartebeest Sanctuary. We specifically assessed how the abundances of the species } \\
\text { differ between fire-burnt (hereafter referred to as disturbed sites) and unburnt (hereafter } \\
\text { referred to as undisturbed) sites across season, and how their responses coincide with } \\
\text { that of some co-existing mammal species. Both disturbance and season, as well their } \\
\text { interaction had statistically significant effects on mean number of individuals of } \\
\text { Swayne's hartebeest; disturbed sites had greater number of individuals than } \\
\text { undisturbed sites and greater mean number was recorded during wet season compared } \\
\text { to dry season. This trend was also revealed when different age categories of the } \\
\text { species were separately considered. The findings of this study highlights the } \\
\text { importance of fire as a potential habitat management tool for effective conservation of } \\
\text { Swayne's Hartebeest population in Senkelle Sanctuary, perhaps due to its effect on the } \\
\text { growth of new grass and increased forage species diversity. However, this result should } \\
\text { be interpreted cautiously as fire in the area are often unplanned and set illegally by local } \\
\text { people. Although we suggest that regulated/planned burning of the habitat is needed for } \\
\text { effective conservation of this globally threatened, endemic subspecies, application of } \\
\text { fires should be conducted based on adequate knowledge (i.e. using the results of } \\
\text { experimentally executed studies as a guide) of the frequency and severity of fire } \\
\text { required to get optimum outcome. } \\
\text { copyright@2015 STAR Journal, Wollega University. All Rights Reserved. }\end{array}$} & $\begin{array}{l}\text { Article Information } \\
\text { Article History: }\end{array}$ \\
\hline & Received : 12-02-2015 \\
\hline & Revised : 13-05-2015 \\
\hline & : 01-06-2015 \\
\hline & Keywords: \\
\hline & Alcelaphus buse \\
\hline & Fire \\
\hline & Savanna \\
\hline & Conservation management \\
\hline & Endangered \\
\hline & \\
\hline & \\
\hline & \\
\hline & Addisu Asefa \\
\hline & \\
\hline & \\
\hline
\end{tabular}

\section{INTRODUCTION}

Swayne's Hartebeest (Alcelaphus buselaphus swaynei) is one of the eight subspecies of Kongoni hartebeest (Alcelaphus buselaphus; family: Bovidae) (Kingdon, 2003; IUCN, 2013). Although its geographical distribution was wide in the past (occurring in Ethiopia, Somalia and Sudan), it only occurs in Ethiopia at present; thus is endemic to the country (IUCN, 2013). Even in Ethiopia, its distribution and population size has been declining substantially and the two largest populations remaining in the country are found in Senkelle Swayne's Hartebeest Sanctuary (SSHS) and Maze National Park (Abiot Hailu, 2013). Currently it is globally considered as an endangered subspecies due to declining population and habitat degradation (IUCN, 2013). Swayne's Hartebeest prefers to live in open, slightly bushed and tall grass woodland areas. They are social animals living in herds of 4 to 30 animals and sometimes aggregate up to 300 to 10,000 individuals (Tewodros Kumssa, 2006;
Vreugdenhil et al., 2012). Generally they are grazers but sometimes browse low shrubs and herbaceous plants (Kingdon, 2000; Tewodros Kumssa, 2006).

SSHS was established in 1971 to protect the endangered and endemic Swayne's Hartebeest population (Hillman, 1993). However, their habitat in the sanctuary has been dramatically decreasing through time (e.g. from $200 \mathrm{~km}^{2}$ to $50 \mathrm{~km}^{2}$ only in 1972/73) due to the expansion of illegal settlements and mechanized farming (Tischler, 1975; Messana and Bereket Netsereab, 1994). This has resulted to decline in population size of the species (e.g. its population size in the Sanctuary was 2379 individuals in 1988 but declined to 123 individuals 1998 (Messana and Bereket Netsereab, 1994; Nishizaki, 2004). Therefore, effective management strategies (e.g. increasing suitable habitat size and improving habitat 
quality) should be in place to ensure the long-term survival of the species.

In Savanna ecosystem, fire is one important management tool to improve wildlife range conditions as it leads to increased plant species diversity, control of undesirable species (e.g. exotic species) and improved palatability of grasses (Dyer, 2002; NRCS, 2006; Almaz Tadesse, 2009). Swayne's Hartebeests are grazers relying on medium to long grasses (Hofmann, 1968; Tewodros Kumssa, 2006). In SSHS they share the limited forage resources with livestock. During dry season particularly, grasses in the Sanctuary become very tall and unpalatable coarse dry, and harbor animal ectoparasites, resulting grassland habitats into poor condition both for the Hartebeest and livestock (Tewodros Kumssa, 2006; Abiot Hailu, 2013). Consequently, the local pastoralists set unregulated and illegal fire to the grasslands with the intention to stimulate the growth of new grass for and to control pests of their livestock (Abiot Hailu, 2013). However, the effect of this uncontrolled fire burning on habitat use of the Swayne's hartebeest in the Sanctuary has not been examined yet. Given that fire has both advantageous and disadvantageous on wildlife habitats, depending on its frequency and intensity (Dyer, 2002; NRCS, 2006), understanding of the responses of Hartebeests to the current uncontrolled fire is of great importance to managers of the Sanctuary to develop appropriate habitat management strategies. This is particularly true since improving the habitat quality of the Sanctuary for Hartebeests is recently identified as the top priority management action needed to secure their longterm survival (Kinahan, 2014). The objective of this study was to examine the response of Swayne's Hartebeest to habitat change due to fire disturbance in the SSHS. We specifically assessed how the abundances of the species differ between fire-burnt (hereafter referred to as disturbed sites) and unburnt (hereafter referred to as undisturbed) sites across season, and how the different age categories (adult, subadult and juveniles) of the Hartebeest might be affected by the disturbance. Furthermore, while we were primarily interested in Hartebeest, we also assessed the response of two other co-existing medium-/large-sized grazer mammal species (common warthog Phacochoerus africanus and Oribi Ourebia Ourebi). We did so to understand if there might be relationships in habitat use between them and Hartebeests which in turn could help to assess if the presence of these species may influence the distribution of Hartebeest due to potential food competition between them.

\section{MATERIALS AND METHODS}

\section{Study Area}

SSHS is located in west side of the Great Rift Valley of Ethiopia, in the West Arsi zone of Oromia Regional State at $305 \mathrm{~km}$ south of the capital Addis Ababa (Geographical location: $7^{\circ} 07^{\prime}$ to $7^{\circ} 12^{\prime} \mathrm{N}$ and $38^{\circ} 18^{\prime}$ to $\left.38^{\circ} 19^{\prime} \mathrm{E}\right)$. With an area of $54 \mathrm{~km}^{2}$, see the below map (Figure 1), it represents the smallest protected area in Ethiopia (Fekadu Debushe et al., 2009). The sanctuary was designated in 1976 primarily to protect population of the endemic, endangered subspecies Swayne's hartebeest. The altitude of the area ranges from 1904 to $2211 \mathrm{~m}$ a.s.l. (Fekadu Debshe et al., 2009).

Senkelle area is characterized by a moderately bimodal pattern of rainfall, receiving annually 600-1200 $\mathrm{mm}$ rain (Abiot Hailu, 2013). Rainfall usually occurs during
February - April, and from June to September; October January being dry season. Mean monthly temperature is relatively constant throughout the year, but diurnal variations can be considerable, with $8 \mathrm{dc}-26 \mathrm{dc}$ minimum and maximum, respectively (Tewodros Kumssa, 2006). The vegetation in the sanctuary consists of savanna woodland, grassland and bush/shrubland (Messana and Bereket Netsereab, 1994). SSHS harbors at least 16 medium-large mammal and 167 bird species (Messana and Bereket Netsereab, 1994).

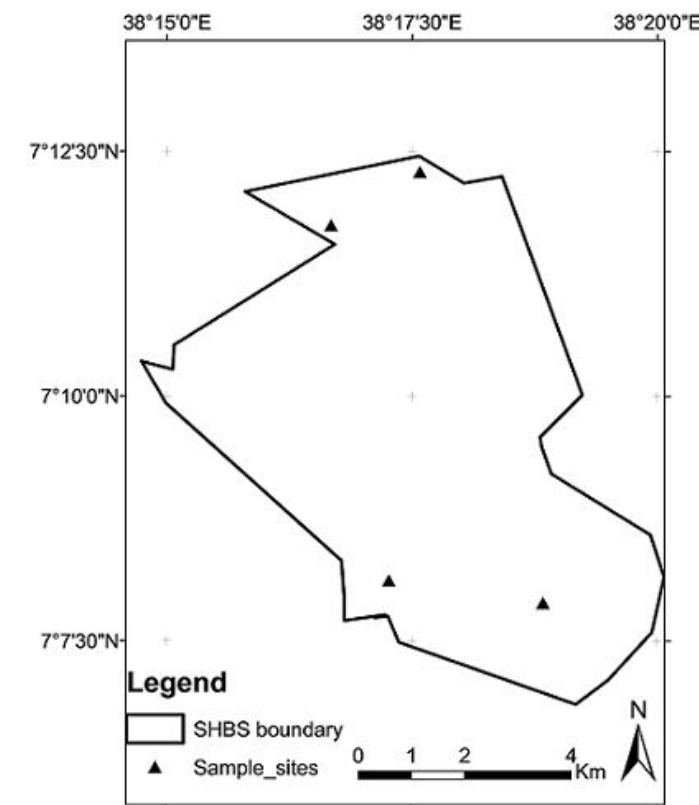

Figure 1: Location of the sample sites in the Senklle Swayne's Hartebeest Sanctuary (SHBS).

\section{Data Collection}

The sanctuary has six functional ranger out-posts for the management purpose. Study sites were selected at four of these outposts by virtue of the relatively effective law enforcement practiced around the outposts, thus represent sites where relatively undisturbed grassland habitats occur. At each of the four sites, two transect lines (one for each of the undisturbed site and disturbed site), each $\sim 2 \mathrm{~km}$ long, were systematically established in the grassland vegetation type. Grassland vegetation type was selected for this study among the three vegetation types discussed above, as it is the most preferred habitat type by Hartebeests in the Sanctuary (Messana and Bereket Netsereab, 1994). The minimum distance between each transect at each site was $400 \mathrm{~m}$. Following Sutherland (1996) for counting medium-/larger-sized animals in open habitats, animals of each species were counted within $200 \mathrm{~m}$ width on both sides of each transect (see also Kangwana, 1996). The census was undertaken twice a week for a period of two months in each of dry season (in December and January 2012) and wet (in July and August 2012). Thus each transect was visited 32 times (16 times in each season) during the course of the study.

Information recorded during each observation was group size (for all the three species) and number of each age category of Hartebeest. Age was determined based on body size and morphological features such as shape and size of horns and recorded regardless of their sex as adult, subadult and juvenile (immature/young, weaned and suckling calves) (Kingdon, 2003). 
Abiot Hailu et al.,

\section{Data Analysis}

The average number of individuals of each species recorded during each counting session was calculated for each transect, separately for each season, and used as sampling units. This was made due to two main reasons. First, data collected repeatedly along each transect are often assumed to be not statistically independent samples (.i.e. they are pseudo-replicates). Such actually nonindependent samples are assumed to potentially affect results and inferences made if treated as independents (Quinn and Keough, 2002). Statistical analyses procedures such as Repeated ANOVA analysis are robust to handle such situations (Quinn and Keough, 2002). However, this was found to be not suitable in the present case as no/few individuals were encountered along some transects during most of the survey sessions. Thus average values discussed above were used for analysis.

The effects of disturbance and season, and their interaction, on number of individuals of each species were examined using a generalized linear model with log-link function and poison probability distribution, an appropriate model for count data (Quinn and Keough, 2002). For Swayne's Hartebeest, a species for which accurate information on age category of each individual was possible to record, this analysis was also conducted for each age category. Finally, to see if the distribution/habitat use of Swayne's Hartebeest might be affected due to the presence of potentially competing species, simple
Sci. Technol. Arts Res. J., April-June 2015, 4(2): 122-126

correlation tests were conducted between the abundance of Swayne's Hartebeest and that of Oribi, and common warthog. All these analyses were undertaken in SPSS version 20 statistical package.

\section{RESULTS}

Both disturbance and season, as well their interaction had statistically significant effects on mean number of individuals of Swayne's hartebeest; disturbed sites had greater number of individuals than undisturbed sites and greater mean number was recorded during wet season compared to dry season (Table 1). Mean abundance of the species in the undisturbed sites during dry season was significantly lower than the other data sets (Figure 2). For Oribi and common warthog, only season had a significant effect on their mean number of individuals, mean abundance during the wet season being greater than dry season (Table 1). For both species wet season data of the disturbed site had significantly greater mean abundance than that of the dry season of this site and dry and wet seasons of the undisturbed site (Figure 2). Regardless of disturbance and season, the abundance of Swayne's Hartebeest showed positive correlations with both Oribi and common warthog, but significant correlation was found only for Oribi (Oribi: Pearson $r=$ 0.78 ; Spearman rho $=0.50$, in both cases $\mathrm{n}=16, P<0.05$; warthog: $r=0.78$; rho $=0.50$, in both cases $n=16$, $P>0.05)$.

Table 1: Mean abundances of Swayne's Hartebeest, Oribi and common warthog in the disturbed and undisturbed sites across dry and wet seasons in SSHS and results of generalized linear analysis.

\begin{tabular}{|c|c|c|c|c|c|c|c|}
\hline \multirow{3}{*}{ Species } & \multicolumn{4}{|c|}{ Mean estimates } & \multicolumn{3}{|c|}{ Tests of Model Effects } \\
\hline & \multicolumn{2}{|c|}{ Disturbance } & \multicolumn{2}{|l|}{ season } & \multirow{2}{*}{ Source } & \multirow{2}{*}{$\begin{array}{c}\text { Wald } \\
\text { Chi-Square }\end{array}$} & \multirow{2}{*}{ Sig. } \\
\hline & Disturbed & undisturbed & dry & wet & & & \\
\hline \multirow[t]{4}{*}{ Hartebeest } & $13.78 \pm 1.32$ & $5.53 \pm 0.96$ & $5.36 \pm 0.94$ & $14.22 \pm 1.34$ & Intercept & 477.600 & * \\
\hline & & & & & disturbance & 21.148 & * \\
\hline & & & & & season & 24.180 & * \\
\hline & & & & & season * disturbance & 9.590 & * \\
\hline \multirow[t]{4}{*}{ Oribi } & $11.04 \pm 1.26$ & $7.93 \pm 1.06$ & $5.56 \pm 0.84$ & $15.76 \pm 1.41$ & Intercept & 648.979 & * \\
\hline & & & & & disturbance & 3.542 & n.s. \\
\hline & & & & & season & 35.267 & * \\
\hline & & & & & season * disturbance & 0.009 & n.s \\
\hline \multirow[t]{4}{*}{ Warthog } & $7.94 \pm 1.08$ & $7.90 \pm 1.00$ & $5.51 \pm 0.84$ & $11.38 \pm 1.21$ & Intercept & 498.366 & ${ }^{*}$ \\
\hline & & & & & disturbance & 0.001 & n.s \\
\hline & & & & & season & 15.295 & * \\
\hline & & & & & season * disturbance & 4.890 & * \\
\hline
\end{tabular}

${ }^{*}$ significant at $\alpha=0.05 ;$ n.s. $=$ non-significant

Table 2: Mean abundances of the three age categories of Swayne's Hartebeest in the disturbed and undisturbed sites across dry and wet seasons in SSHS and results of generalized linear analysis

\begin{tabular}{|c|c|c|c|c|c|c|c|}
\hline \multirow{3}{*}{ Age } & \multicolumn{4}{|c|}{$\begin{array}{c}\text { Mean estimates } \\
\end{array}$} & \multicolumn{3}{|c|}{ Tests of Model Effects } \\
\hline & \multicolumn{2}{|c|}{$\begin{array}{l}\text { Disturbance } \\
\end{array}$} & \multicolumn{2}{|l|}{ season } & \multirow{2}{*}{ Source } & \multirow{2}{*}{$\begin{array}{c}\text { Wald } \\
\text { Chi-Square }\end{array}$} & \multirow[t]{2}{*}{ Sig. } \\
\hline & Disturbed & undisturbed & dry & wet & & & \\
\hline \multirow[t]{4}{*}{ Adult } & $6.07 \pm 0.88$ & $2.80 \pm 0.68$ & $2.44 \pm 0.61$ & $7.00 \pm 0.94$ & intercept & 98.659 & * \\
\hline & & & & & disturbance & 7.396 & * \\
\hline & & & & & season & 13.561 & * \\
\hline & & & & & season * disturbance & 3.860 & n.s. \\
\hline \multirow[t]{4}{*}{ Subadult } & $3.87 \pm 0.70$ & $1.87 \pm 0.53$ & $2.00 \pm 0.56$ & $3.62 \pm 0.67$ & intercept & 34.816 & * \\
\hline & & & & & disturbance & 4.700 & * \\
\hline & & & & & season & 3.133 & n.s \\
\hline & & & & & season * disturbance & 3.851 & n.s. \\
\hline \multirow[t]{4}{*}{ Juvenile } & $3.71 \pm 0.70$ & $0.79 \pm 0.41$ & $0.83 \pm 0.43$ & $3.54 \pm 0.68$ & intercept & 3.729 & n.s \\
\hline & & & & & disturbance & 7.700 & * \\
\hline & & & & & season & 6.779 & * \\
\hline & & & & & season * disturbance & 2.342 & n.s \\
\hline
\end{tabular}


Considering the three different age categories of Swayne's Hartebeest, both disturbance and season had significant effects on their mean abundances, except the non-significant effect of season on mean abundance of subadults (Table 2). For all age groups dry season data of the undisturbed sites tended to contain lower mean abundance than the dry season abundance of the disturbed sites and the wet season abundances of both the disturbed and undisturbed data sets (Figure 3).

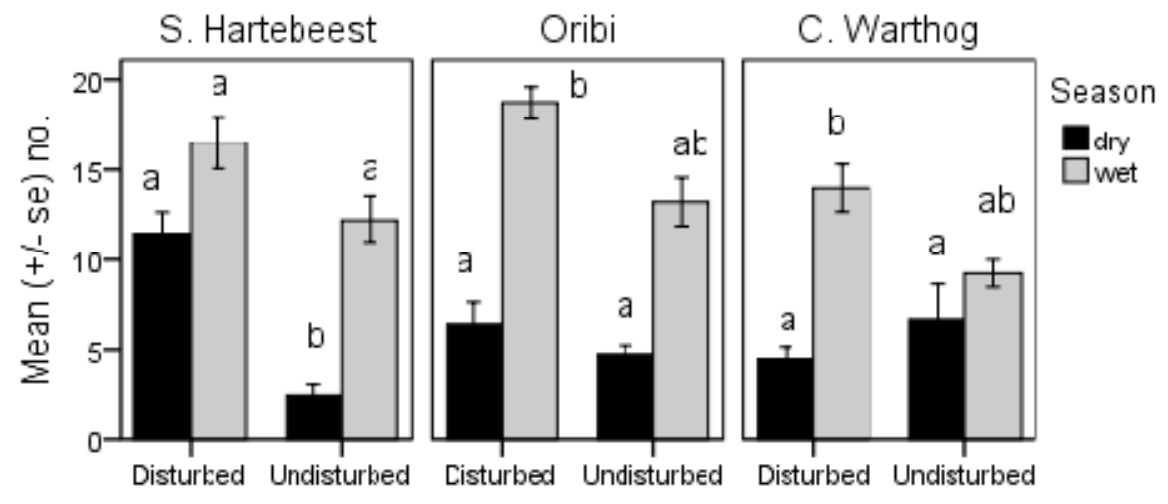

Figure 2: Mean comparison of Swayne's Hartebeest (S. Hartebeest), Oribi and Common Warthog (C. Warthog) in the disturbed and disturbed sites across seasons. Different letters for each species indicates significant differences.

\section{DISCUSSION}

This study demonstrated that fire disturbance, independently or interactively with season, had significant effect on the abundance of the endangered endemic subspecies Swayne's Hartebeest population in the SSHS. Disturbed sites generally tended to contain greater number of individuals of Hartebeests than undisturbed sites and this difference was more pronounced during dry season when forage resources are scarcely available (Tewodros Kumssa, 2006). These effects were also reflected on the different age categories of the species. Although the distribution/habitat use of Oribi and Common warthog was generally correlated with that of Hartebeests, the effect of disturbance on their abundance was weak and non-significant. Nonetheless, similar to Hartebeests, their mean abundances were significantly greater during the wet season compared to dry season abundance.

Fire has been considered as the principal range-land management tool in savanna ecosystems; it often leads to increased plant species diversity and improved quality of forages (Dyer, 2002; NRCS, 2006; Almaz Tadesse, 2009). In the present study area, Abiot Hailu (2013) has reported increased species richness, diversity and abundance of forage plants in fire-disturbed sites compared to undisturbed sites. Thus the findings that the greater number of Hartebeests in the disturbed sites compared to the undisturbed sites could be attributed to improved habitat condition by fire, implying the positive effect of fire on the species' habitat in the study area. Studies in African savanna ecosystems (e.g. Queens Elizabeth National Park of Uganda [Jaksic-Born, 2009; Plumptre et al., 2010]) also reported similar positive responses of several wildlife ungulate species to fireinduced habitat disturbance. However, the positive effect reported in the present sudy should be interpreted cautiously as these fires are unregulated and illegally applied by local people. Such unregulated fire has also been reported to have negative consequences on different ecosystems and associated biota (Syms and Jones, 2000 Jaksic-Born, 2009). Depending on the frequency, intensity and time of burning, fire can cause complete replacement of habitats via native bush encroachments and invasion alien species (Jaksic-Born,
2009; Plumptre et al., 2010), a situation have reported in several protected areas of Ethiopia including SSHS (Abiot Hailu, 2013).

In SSHS grasses reach their maximum height and become dry during the dry season, thus are assumed to be unpalatable to the Hartebeests (Messana and Bereket Netsereab, 1994; Tewodros Kumssa, 2006). Consequently, Hartebeests usually avoid open grassland areas (both disturbed and undisturbed sites) and move down drainage lines in finding of grass and water during this season (Kingdon, 2003; Tewodros Kumssa, 2006), perhaps explaining the seasonal differences observed in Hartebeest abundance in the study sites. However, the abundance of Swayne's Hartebeest did not show significant difference between the disturbed and undisturbed sites during wet season. This may suggest that foraging resources and water are not limiting factors (i.e. abundant in both disturbed and undisturbed sites) during this season (Tewodros Kumssa, 2006; Abiot Hailu, 2013).

In addition to disturbance other ecological factors, other ecological factors such as proximity to water sources, the presence of other species (e.g. livestock, grazer wildlife and predators) and differences in detectability of animals due to differences in habitat structure between sites could also be underlying reasons for the differences in abundance of animals between sites. However, these issues seem to be minimal in the case of the Hartebeest for the following reasons. First, the study sites are located almost at equidistance from watering points. Second, Hartebeests were more abundant in the disturbed sites where livestock were also abudnat (Abiot Hailu, 2013). Third, Hartebeests showed positive correlation with potential competing wildlife species (i.e. Warthog and Oribi). Finally, although the issue of detectabiliy may particularly be considerable for elusive and small-/medium-sized species such as Oribi and Warthog (Sutherland, 1996), this effect seems to be negligible as dry season (when vegetation height is most distinct between burnt and unburnt sites) abundances of these two species, and of juveniles of Hartebeest, were similar between sites. 


\section{CONCLUSION}

The findings of the present study highlights the importance of fire as a potential habitat management tool for effective conservation of Swayne's Hartebeest population in Senkelle Sanctuary, perhaps due to its effect on the growth of new grass and increased forage species diversity (Abiot Hailu, 2013). However, given that fire is also one major environmental factor that could cause undesirable effects to ecosystems and it favors the growth and establishment of invasive alien species and encroachment of indigenous bush species (Tewodros Kumssa; 2006; Wondimagegnehu Tekalign and Afework Bekele, 2011; Yosef Mamo et al., 2012). These results should have be seen carefully as fire in the area is usually set by locals without appropriate plan and design. Although we suggest that regulated/planned burning of the habitat is needed for effective conservation of this globally threatened and endemic subspecies, application of fires should be conducted based on adequate knowledge (i.e. using the results of experimentally executed studies as a guide) of the frequency and severity of fire required to get optimum outcome.

\section{Acknowledgments}

We would like thank ecologists of SSHS staff for their assistance during data collection. This study was undertaken by financial support provided by GIZSustainable Development of the Protected Area System of Ethiopia project. The first author is grateful to the Wondo Gennet College of Forestry \& Natural Resources, Hawassa University for offering MSc studentship. We are grateful to the Ethiopian Wildlife Conservation Authority for the research permission provided.

\section{Coflict of Interest}

Authors don't have any conflict of interest.

\section{REFERENCES}

Abiot Hailu (2013). Effect of habitat disturbance on the population of Swayne's Hartebeest (alcelaphus buselaphus swaynei) in Senkelle Swayne's Hartebeest Sanctuary. MSc Thesis School of Wildlife Management and Ecotourism Studies, Wondo Genet College of Forestry and Natural Resources, Hawassa, Ethiopia.

Almaz Tadesse (2009). Sustaining the Allideghi grassland of Ethiopia: influences of pastoralism and vegetation change. PhD Dissertation, Utah State University, Utah, USA.

Dyer, A.R. (2002). Burning and grazing management in California grassland: effect on bunchgrass seed viability. Restoration Ecology 10(1): 107-111.

Fekadu Debushe, Abdi Itana, Yebeltal Alemu and Arega Mekonnen (2009). Boundary Survey and socio-economic assessment for the re-demarcation of Senkelle Swayne's Hartebeest Sanctuary. Ethiopian Wildlife Conservation Authority, Addis Ababa, Ethiopia, 38 pp.

Hillman, J.C. (1993) Ethiopia: Compendium of Wildlife Conservation Information, Vols.1 and 2. Ethiopian Wildlife Conservation Organization, Addis Ababa, Ethiopia.

Hofmann, R.R. (1968). Comparisons of the rumen and omasum structure in East African game ruminants in relation to their feeding habits. Symposium of the Zoological Society of London 21: 179-194.

International Union for Conservation of Nature and Natural resources (IUCN) (2013). IUCN SSC Antelope Specialist
Group-Alcelaphus buselaphus ssp. swaynei. IUCN Red List of Threatened Species, Version 2013. [Available online:http://www.iucnredlist.org. accessed on 6/11/2013].

Jaksic-Born, C. (2009). Effects of anthropogenic disturbances on the distribution and abundance of large herbivores in Queen Elizabeth National Park, Uganda. Unpublished PhD Thesis, University of Basel, Switzerland.

Kangwana, K. (1996). Studying Elephants. African Wildlife Foundation (AWF) Technical Handbooks Series. AWF, Nairobi, Kenya. (2014).

Kinahan, A.A. (2014). Ecological and Threat Monitoring Priorities for Senkelle Hartebeest Sanctuary, Ethiopia. Ethiopian Wildlife Conservation Authority, Addis Ababa, Ethiopia. 47pp.

Kingdon, J. (2003). The Kingdon Field Guide to African Mammals, $3^{\text {rd }}$ edi. Christopher Helm, London, England.

Messana, G.M., Bereket Netsereab (1994). The Senkelle Swayne's Hartebeest Sanctuary Management Plan. Ethiopian Wildlife Conservation Department, Addis Ababa, Ethiopia.

Natural Resources Conservation Service (NRCS) (2006). Importance of disturbance in habitat management. Fish and Wildlife Habitat Management Leaflet 37:11.

Nishizaki, N. (2004). Resisting imposed wildlife conservation Arssi Oromo and the Senkelle Swayne's Hartebeest Sanctuary, Ethiopia. African Study Monographs 5:61-77.

Plumptre, A.J., Kirunda, B., Mugabe,H., Stabach, J., Driciru, M., Picton-Phillipps, G., Ayebare, S., Nangendo, G. and N.Laporte, N. (2010). Impacts of fire and large mammals on the ecology of Queen Elizabeth Park, Uganda. Wildlife Conservation Society and Woods Hole Research Centre.

Quinn, G.P., Keough, M.J. (2002). Experimental design and data analysis for biologists, $1 \mathrm{st}$ edn. Cambridge University Press, Cambridge, UK. 537pp.

Sutherland, W.J. (1996). Ecological Census Techniques. A handbook. Cambridge University Press, Cambridge, UK.

Syms, C., Jones, G.P. (2000). Disturbance, habitat structure, and the dynamics of a coral-reef fish community. Ecology 81(10): 2714-2729.

Tewodros Kumssa (2006). Human-Wildlife conflict and population status of Swayne's Hartebeest (Alcelaphus buselaphus swaynei) in Senkelle Swayne's Hartebeest Sanctuary. M.Sc. thesis, Addis Ababa University, Ethiopia.

Tischler, T.H. (1975). Deprive for Swayne's Hartebeest. Walia 6: 12-13.

Vreugdenhil, V.D., Astrid, M., Tamirat Tilahun, Anteneh Shimeis and Zelealem Tefera (2012). Gap analysis of the protected areas system of Ethiopia. World Institute for Conservation and Environment, Washington DC, USA. $185 \mathrm{pp}$.

Wondimagegnehu Tekalign, Afework Bekele (2011). Current population status of the endangered endemic subspecies of Swayne's Hartebeest (Alcelaphus buselaphus swaynei) in Maze National Park, Ethiopia. SINET: Ethiopian Journal of Science 34(1): 39-48.

Yosef Mamo, Girma Mengesha, Kefale Shale, Armde Fetene Mezmur Girma (2012). Status of the Swayne's Hartebeest (Alcelaphus buselaphus swaynei) meta-population under land cover changes in Ethiopian Protected Areas. International Journal of Biodiversity and Conservation 4: 416-426. 